\title{
Design workshop with farmers as a promising tool to support the introduction of diversifying crops within a territory: the case of camelina in northern France to supply a local biorefinery ${ }^{\text {in }}$, 你䜤
}

\author{
Margot Leclère*, Marie-Hélène Jeuffroy and Chantal Loyce \\ Université Paris-Saclay, INRAE, AgroParisTech, UMR Agronomie, Avenue Lucien de Brétignières, 78850 Thiverval-Grignon, France
}

Received 8 April 2021 - Accepted 17 June 2021

\begin{abstract}
The development of local diversification value-chains requires the design and implementation of cropping systems adapted to a diversity of farms and the management of crops for which very little knowledge is available. In this article, using the example of camelina in northern France to supply a local oilseed biorefinery, we illustrate how (i) the realisation of a design workshop based on the formalization and sharing of local knowledge produced by a multi-stakeholder participatory approach, and (ii) the analysis, formalization and sharing of the outputs of this design workshop, are useful for supporting the introduction of a new species in a territory. In total, each of the nine farmers attending the workshop designed one (or two) proposal(s) to include and manage camelina adapted to their own situation. The precise description of these proposals and the explanation of the technical choices, the identification of the factors explaining the diversity of the proposals designed, as well as the inventory of the functions expected of the crop by the farmers, which are presented in this paper, constitute a set of elements that could also be used to support other farmers in the area who would like to introduce this new species into their cropping system.
\end{abstract}

Keywords: diversification / local value-chain / knowledge formalization / participatory design

\begin{abstract}
Résumé - L'atelier de conception, un outil prometteur pour accompagner l'introduction d'espèces de diversification dans les territoires : exemple de la cameline dans le nord de la France pour approvisionner une bioraffinerie oléagineuse locale. Le développement de filières locales de diversification suppose la conception et la mise en œuvre en parcelles agricoles de systèmes de culture adaptés à une diversité d'exploitations agricoles et intégrant des cultures pour lesquelles très peu de connaissances sont disponibles. Dans cet article, en nous appuyant sur l'exemple de la cameline dans l'Oise pour approvisionner une bioraffinerie oléagineuse locale, nous illustrons en quoi (i) la réalisation d'un atelier de conception basé sur la formalisation et le partage de connaissances uniquement locales, de différentes natures et produites par une démarche participative multi-acteurs et (ii) l'analyse, la formalisation et le partage des sorties de cet atelier de conception, sont utiles pour accompagner l'introduction d'une nouvelle espèce dans un territoire. Au total, chacun des neuf agriculteurs présents à l'atelier a conçu une (ou deux) modalité(s) d'insertion et de conduite de la cameline adaptée(s) à sa propre situation. La description précise de ces modalités et l'explicitation des choix techniques, l'identification des facteurs expliquant la diversité des modalités conçues ainsi que le recensement des fonctions attendues de la culture par les agriculteurs, qui sont présentés dans ce papier, constituent un ensemble d'éléments qui pourrait être mobilisables pour accompagner d'autres agriculteurs du territoire qui voudraient introduire cette nouvelle espèce dans leur système de culture (The full text is available in French on https://www.ocljournal.org/10.1051/ocl/2021023/olm).
\end{abstract}

Mots clés : diversification / filière locale / formalisation des connaissances / conception participative

\footnotetext{
ir Contribution to the Topical Issue "Creating new oil \& protein crop value chains / Construire de nouvelles filières oléoprotéagineuses".

सh The French version is available in "Supplementary Material".

*Correspondence: margot.leclere@inrae.fr
} 


\section{Introduction}

The development of value chains based on diversification crops requires the implementation and the combination of genetic, agronomic, technological and organizational innovations (Meynard et al., 2018; Colombo et al., 2020). Such changes are however hindered by the current socio-technical lock-in around major crops, along with the difficulties of coupling the design processes (Magrini et al., 2016; Kuokkanen et al., 2017). At farm level, the lack of scientific and technical knowledge on minor crops, which is characteristic of this lockin, partly explains their limited local and regional development (Zimmer et al., 2016; Meynard et al., 2018). Therefore, the production of knowledge and methods to support, think and assess the introduction of diversifying crops in cropping systems is necessary for the development of new diversification value chains (Morel et al., 2020). In practice, introducing a new crop on a farm implies a redesign, at least partially, of the cropping system concerned. In addition to mapping out the technical itinerary to apply to this crop (i.e. its management), its position in the crop sequence must be determined (i.e. its inclusion) while taking into account the effects of the previous crop and the effects on following crops, by adjusting, if necessary, their management as well (Sebillotte, 1990).

The retrospective analysis of diverse situations in which farmers re-designed their cropping or farming systems, has highlighted: (i) the need to produce and hybridize different kinds of knowledge in action (empirical, scientific) on the object studied; and (ii) the importance of the way in which this knowledge is formalized and shared to stimulate design (Girard and Navarrete, 2005; Toffolini et al., 2017; Catalogna et al., 2018; Girard and Magda, 2018; Lacombe et al., 2018; Quinio et al., 2019; Salembier, 2019). For instance, for tomatoes grown in greenhouse, Navarrete et al. (1997) showed that the translation of management indicators (e.g. plant vigour) used by experienced growers, into reproducible and easily measurable agronomic parameters (e.g. stem diameter), has been useful to support inexperienced farmers in adapting their management practices of climatic conditions in their greenhouse thanks to a decision-making tool (Tchamitchian et al., 2006).

To support farmers in their design work, Reau et al. (2012) have proposed setting up design workshops, a formalized method to collectively explore a range of solutions and then flesh out the details of their implementation in different cropping systems. The authors propose structuring such workshops in three steps, starting with a knowledge-sharing phase tailored to the workshop's objectives. The knowledge shared can refer to: (i) the issues surrounding the design target chosen (e.g. the controversies around the nitrogen-balance method for a workshop focused on designing a new nitrogen fertilization method (Ravier et al., 2018)); (ii) the biophysical processes involved in the targeted results (e.g. the absence of wheat yield loss if it is subjected to temporary nitrogen deficiencies, ibid.); or (iii) the elements of the cropping system that can impact these processes. In the second step, the participants explore technical options or solutions that can contribute to reach the chosen target. These proposals are both mobilising the knowledge shared in the first stage of the workshop and the participants' own knowledge (often more local). The third step consists in collectively designing farming or cropping system(s) for a concrete situation, potentially drawing on the ideas formulated in the previous stage. In France, this method has gained traction and has been taken up by academic researchers and R\&D actors to support the design of innovative cropping systems, agroecological territories, or decision-making tools (Petit and Reau, 2013; Berthet et al., 2014; Plénet and Simon, 2015; Deytieux et al., 2018; LesurDumoulin et al., 2018; Ravier et al., 2018; Pelzer et al., 2020). Despite their shared structure and philosophy, these different design workshops also present considerable diversity in the actors involved, the nature and form of the knowledge shared, the design objects, and the organization of the design process (Jeuffroy et al., forthcoming).

Drawing on a case study, this article illustrates and discusses the potential value, for supporting the introduction of a new crop in a territory, of: (i) holding a design workshop characterized by the formalization and sharing of uniquely local knowledge of various types, produced by a participatory multi-stakeholder approach; and (ii) analysing, formalizing and sharing the outputs of this design workshop.

This work was based on an action research project (20162019) focused on the introduction of camelina (Camelina sativa) in the cropping systems of the Oise département to supply a local oilseed biorefinery. Owing to its agronomic and industrial properties (Berti et al., 2016), this oil crop was identified by the biorefinery project leaders, together with the research team, as a possible source to supply the future biorefinery. However, at the start of the project, no conventional farmer was growing this diversification crop in the potential supply area (within $50 \mathrm{~km}$ around the city of Compiègne). To support farmers' redesign process in this area, an original participatory and multi-stakeholder approach was implemented (Leclère, 2019). The articulation of two experimental on-farm devices and frameworks for dialogue (field visits, results-sharing day, etc.) over a two-year period has stimulated the production of different types of knowledge (scientific and empirical) on this diversification crop, then capitalized in scientific papers (Leclère et al., 2018, 2019, 2021). This knowledge was also shared during a design workshop, which aims were to support the design, by farmers, of camelina inclusion and management modalities tailored to their situation.

After describing the organization of this design workshop and the output analysis methods used, we present the main results of the cross-cutting analysis of the different ways to include and manage camelina, designed by the farmers. Finally, we discuss how the organization of this workshop differs from the design workshop organization formalized by Reau et al. (2012), and how the results of such a workshop could also provide a body of knowledge to support other farmers' design of cropping systems that include camelina.

\section{Materials and methods}

\subsection{General organization of the design workshop}

The design workshop took place over a day in June 2019. Nine farmers from the study area interested in growing camelina in 2019 or 2020 attended the meeting, along with 



Fig. 1. (a) Example of a crop sheet (technical itinerary section) after the transcription by the research team (farmer's remaining questions are in green in the scheme). (b) Collective debriefing of the designed modalities: each farmer describes and explains his proposal to the whole group.

their farm advisor. The participants were chosen with different levels of theoretical and practical knowledge about camelina. The objective was to involve actively new farmers and to be able to scrutinize their ability to design camelina based cropping systems without having participated in the knowledge production phase. Among the nine farmers, five had taken part in at least one of the two experimental devices set up by the research team in previous years ${ }^{1}$ and had therefore grown camelina on their farms. The other four had not participated in either of these experimental devices and had never grown camelina.

The whole day was organized around the following target, proposed by the researchers and approved by the participants: "Where and how would you grow spring or summer camelina (as a second crop) without pesticides, with low inputs and in a way that is profitable, on your farm?". This goal was formulated to: (i) integrate ambitious objectives linked to the future use in biorefinery (crop with a low environmental impact, i.e. pesticide-free and low in inputs); (ii) take into account farmer expectations (particularly regarding the profitability of the new system, integrating this new crop); and (iii) foster both exploration and action, by situating the design on each farmer's situation.

The workshop was organized in three phases and facilitated by the research team. The knowledge-sharing phase was dedicated to reporting on and discussing the results of the different experimental devices previously implemented in the region. It consisted of an oral presentation prepared and performed by the research team (see Sect. 2.2) with discussion

\footnotetext{
1 The first experimental framework (subsequently referred to as "farmer-experimenter trials"), described in Leclère et al. (2018), involved a set of trials with camelina as a second crop that were autonomously designed and evaluated by farmers and observed by the research team. The second experimental framework (hereafter "multienvironment trial network") refers to a "cropping system" experimentation in which five spring camelina management routes (a sole crop or intercropped) were tested in various environments (Leclère et al., 2019, 2021).
}

times to enable the participants to integrate this new knowledge, which was crucial to the exploration during the design phase (Hatchuel and Weil, 2009). The objective of the second phase (the design phase) was to allow the farmers to design different ways to include and manage camelina that they would be willing to implement on their own farms. This phase was divided into two parts: an individual reflection (about 15 minutes), followed by collective debriefing. During the individual reflection session, the farmers were asked to design one (or two) inclusion and management proposal(s) that they formalized in a "crop sheet", proposed by the researchers and comprised of two sections: "Description of the crop sequence including camelina", and "Schematization and description of the main features of the technical itinerary applied to camelina" (Fig. 1a). During the collective debrief (Fig. 1b), farmers presented their proposals in turn, explaining the way to include camelina they had chosen and the associated technical itinerary, and justifying their technical choices with the help of specific questions asked by the research team (about 15 minutes per farmer). During the discussions, the other farmers in the group sometimes proposed alternatives, which were examined and then adopted (or not) by the farmer concerned. Finally, in the summary-discussion phase, all the different proposals were reviewed, and outstanding questions were identified and discussed collectively.

\subsection{Focus on the content and organization of knowledge sharing}

Knowledge from various sources and of different types was presented to the participants during this stage. It all derived from the two experimental frameworks implemented locally between September 2016 and June 2019: a multienvironment trial network, established on farms but monitored by the research team and in which various spring camelina management routes were tested in different environments, and farmer-experimenter trials, in which modalities involving camelina as a second crop were designed, tested and assessed by the farmers on their own farms, autonomously (Tab. 1). 
M. Leclère et al.: OCL 2021, 28, 40

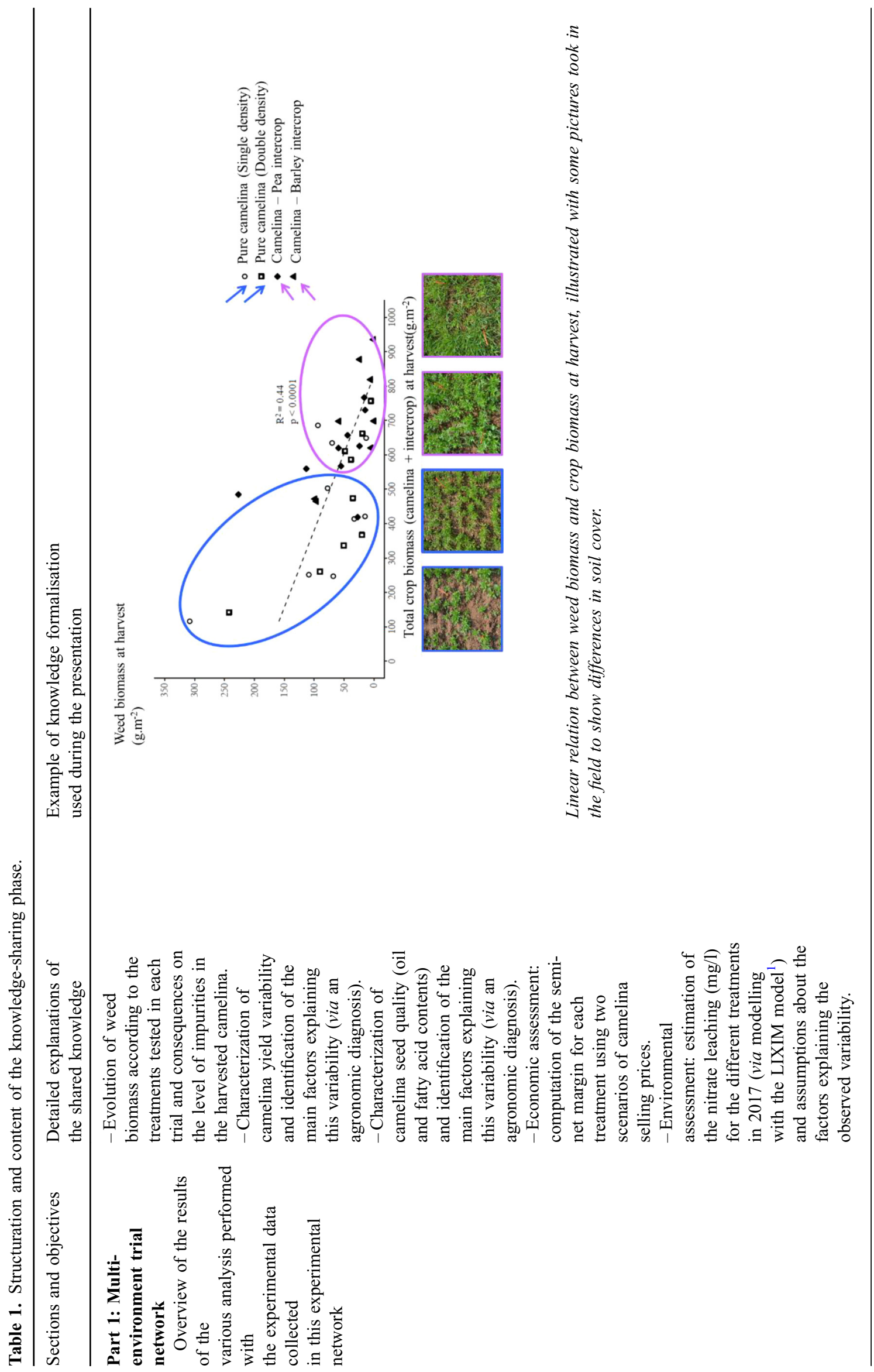

Page 4 of 14 
M. Leclère et al.: OCL 2021, 28, 40
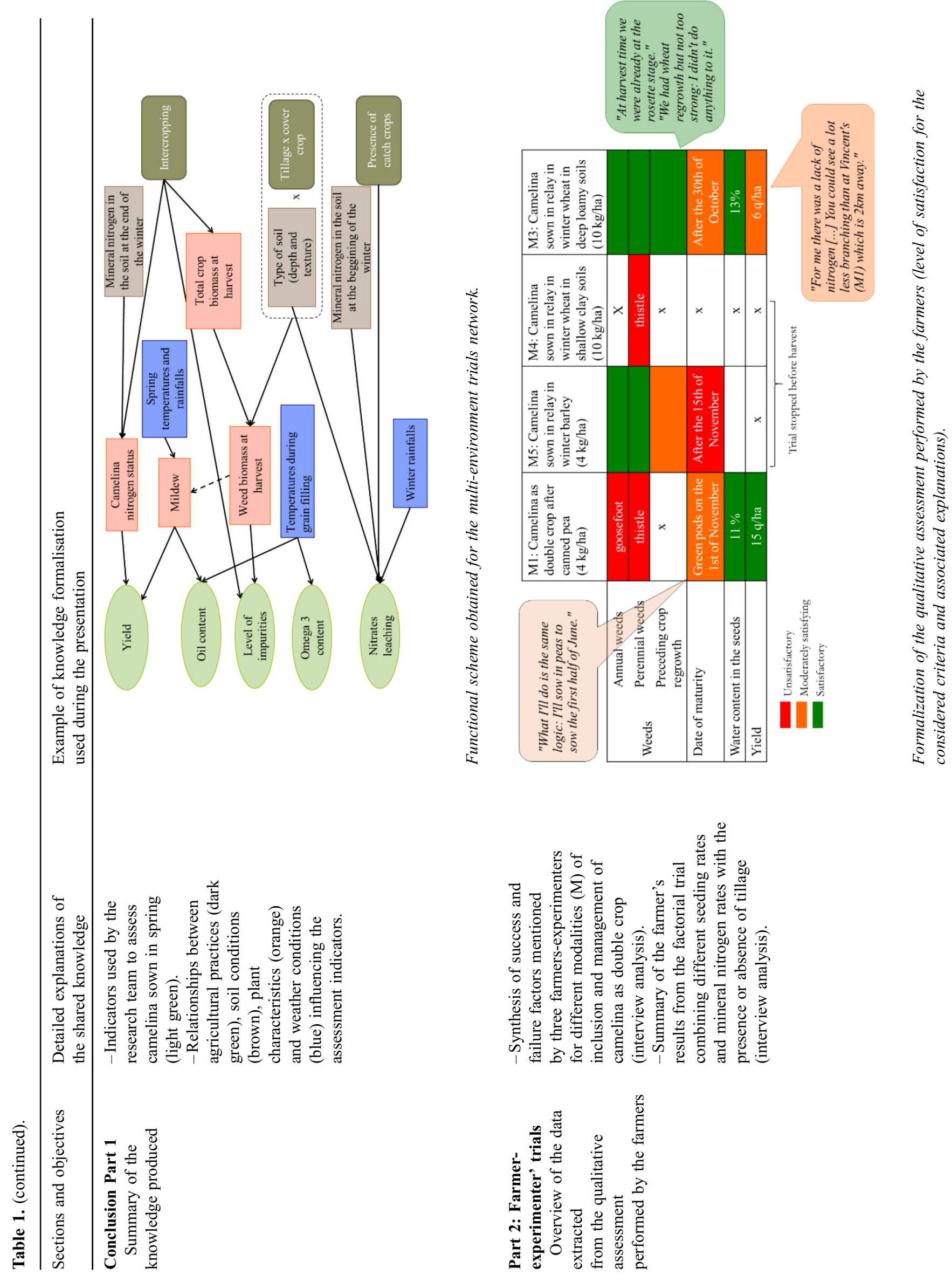
M. Leclère et al.: OCL 2021, 28, 40

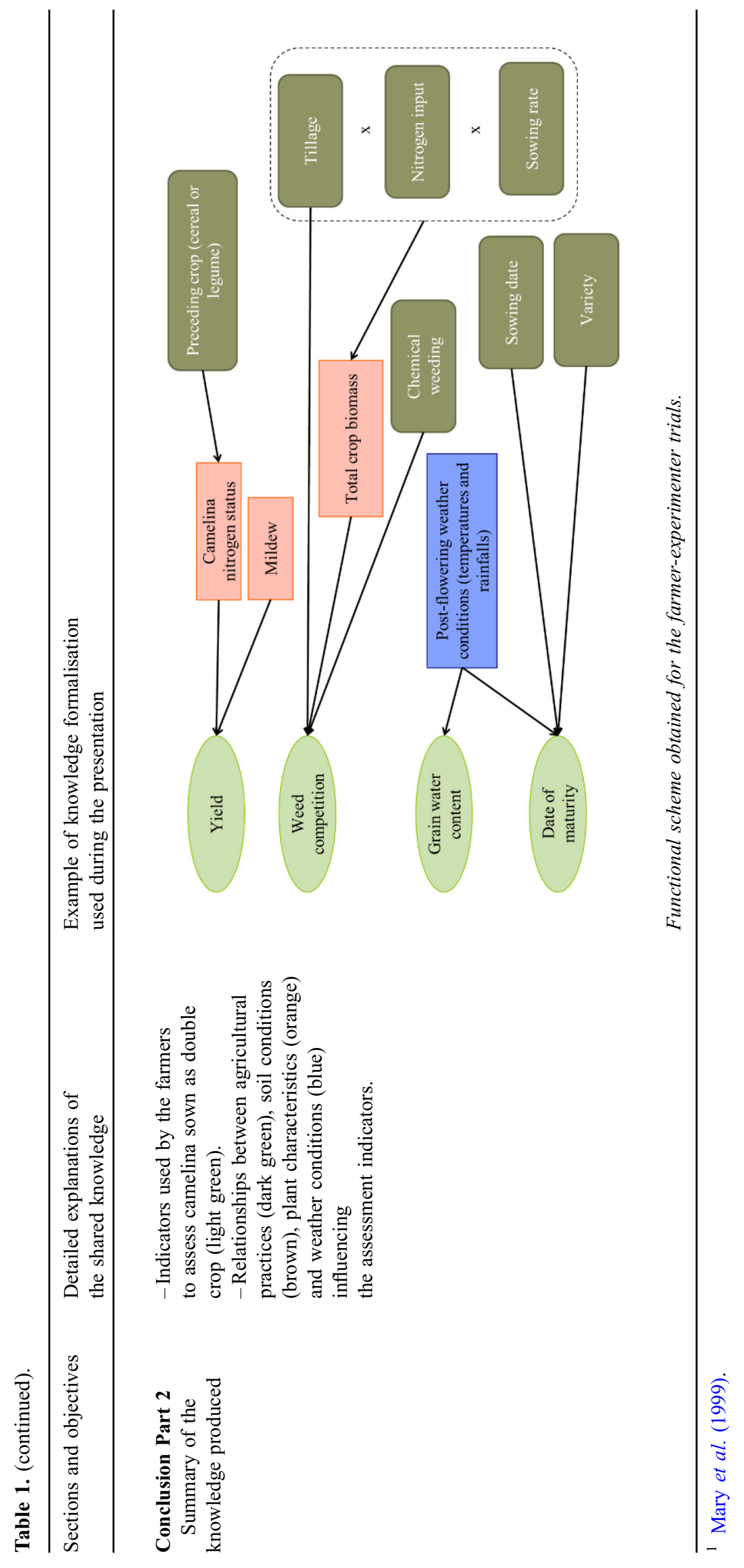

Page 6 of 14 
M. Leclère et al.: OCL 2021, 28, 40

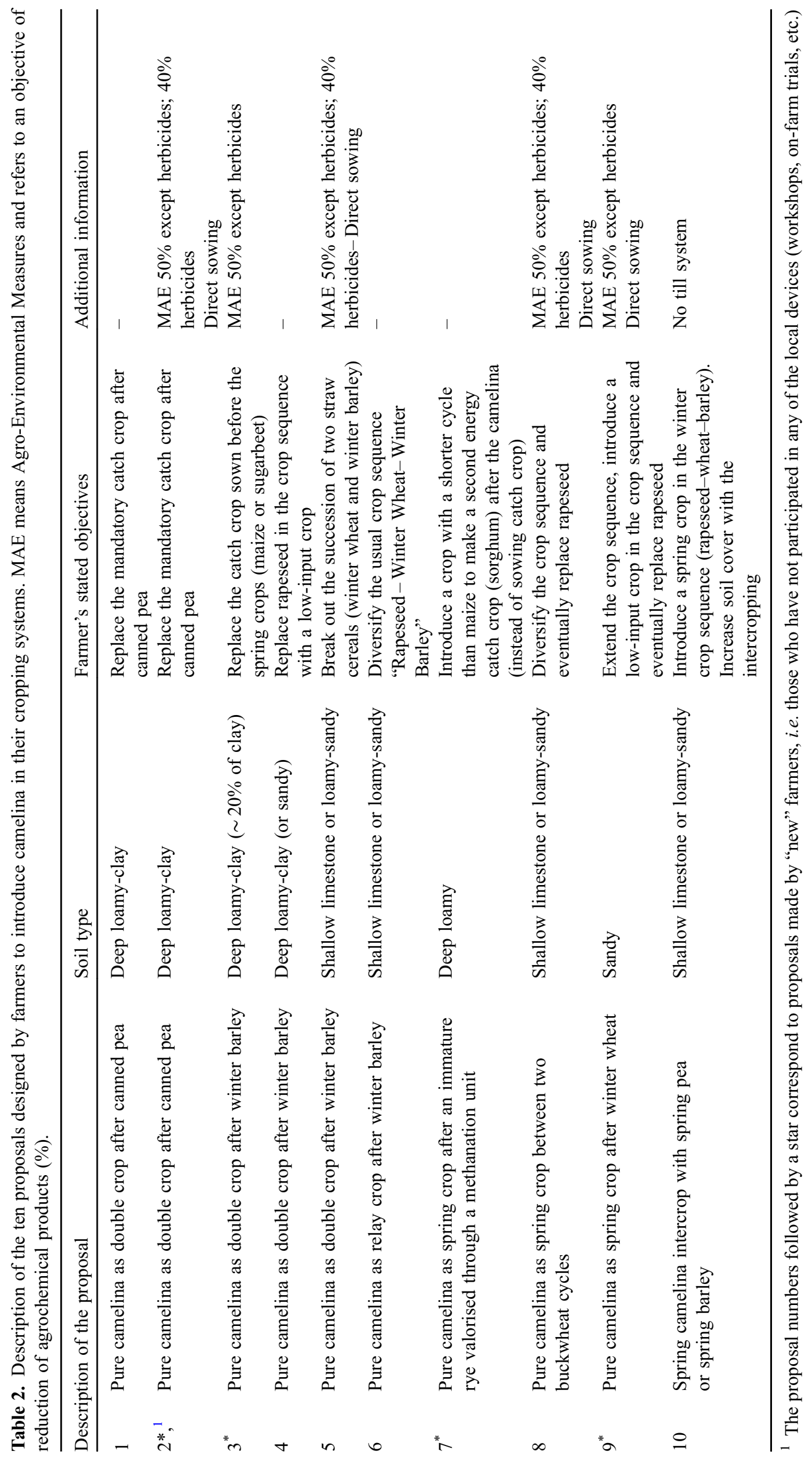




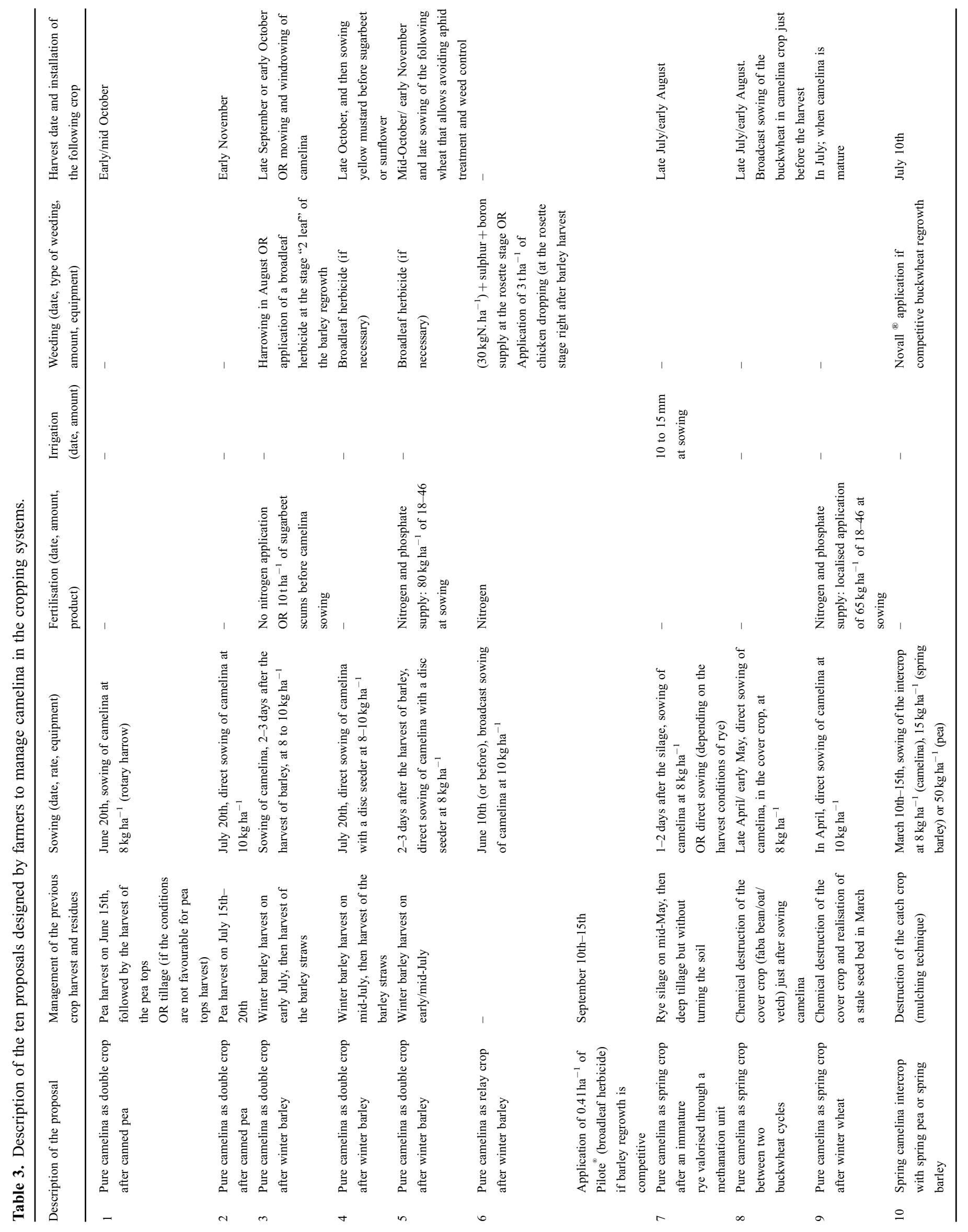


More concretely, the knowledge sharing was structured in three sections: after a general introduction describing the context and explaining the objective of the day, results from the multi-environment trial network were shared, followed by those of the farmer-experimenter trials (Tab. 1). Given the differences in the nature of the knowledge produced by the two experimental devices and in the way to include camelina in the crop sequence (spring vs. summer), the biophysical processes at play were represented differently in each case (Tab. 1). In the case of the multi-environment trial network, we chose to represent the functional relationships between the variables as they had been formalized in the scientific papers, that is, as statistically evaluated linear relationships. However, where possible, this knowledge was illustrated with field observations. In the case of the farmer-experimenter trials no intermediate experimental measurements had been taken to identify relationships between variables. Therefore, the farmers' own understanding, based on their observations and expertise and recorded during interviews, were presented with verbatim, alongside the results of the qualitative assessment (Tab. 1). To conclude each section and put into perspective the knowledge produced through the two experimental devices, two functional schemes were drawn and presented to the participants (Tab. 1). This synthetic representation - generally done before performing an agronomic diagnosis (Lançon et al., 2004; Valantin-Morison and Meynard, 2012) - has been useful to list the indicators used to assess the performance of camelina and present the factors (agricultural practices, environmental conditions, etc.) affecting these indicators. As these factors varied from one experimental device to another, these two representations provided complementary information on the crop.

\subsection{Analysis of the data from the design phase}

Based on the data available (crop sheets provided to the farmers to describe their proposal and then shared collectively, audio recordings, and minutes of the day), two successive analyses were performed. First, an individual analysis of the cropping systems designed was carried out. This stage consisted in transcribing the crop sheets, adding, where appropriate: (i) the alternative proposals explored with the group; and (ii) the questions and uncertainties raised by the farmer (Fig. 1a). For each proposal, this stage also provided clarification on the objective(s) formulated by the farmers during the workshop (e.g. using as few inputs as possible), the technical levers mobilized in the design of the technical itinerary (e.g. opting for mechanical weeding), and potentially the services expected from this crop management option (e.g. the long-term improvement of biological life of the soil), which were mentioned by the farmers. Ten individual reports - one for each proposal-were produced to summarize this information. Next, a cross-cutting analysis of these different individual systems was carried out with three goals: (i) characterizing the wide range of inclusion and management modalities proposed; (ii) identifying the functions expected of camelina by the farmers; and (iii) identifying knowledge gaps to be filled as a priority in order to pursue the design process.

\section{Results}

\subsection{Characterization of the diversity of ways to include and manage camelina designed by farmers}

\subsubsection{Description}

A total of ten camelina inclusion and management modalities were designed by the farmers (Tabs. 2 and 3). Of the ten proposals presented, six consisted in including camelina as a second crop $\left(\mathrm{n}^{\mathrm{o}} 1\right.$ to 6$)$. For these six proposals, camelina was sown either as a double crop after field peas or winter barley, or as a relay crop in winter barley.

Among the four proposals with camelina included as spring crop $\left(\mathrm{n}^{\circ} 7\right.$ to 10$)$, only one corresponded to intercropping $\left(\mathrm{n}^{\mathrm{o}} 10\right)$. When sown as pure crop, camelina was included after various previous crops such as rye, wheat or buckwheat (Tab. 2). For similar ways to include camelina, different crop management routes were proposed (Tab. 3). For camelina as double crop after canned pea $\left(\mathrm{n}^{\mathrm{o}} 1\right.$ and 2$)$, the farmers proposed different sowing dates and rates (June, 20 with a density of $8 \mathrm{~kg} \mathrm{ha}^{-1}$ and July, 20 with $10 \mathrm{~kg} \mathrm{ha}^{-1}$ respectively). Likewise, for the introduction of camelina as double crop after winter barley ( $\mathrm{n}^{\mathrm{o}} 3$ to 5 ), different combinations of techniques were proposed by the farmers to manage barley regrowth in camelina and limit the nitrogen deficit induced by the decomposition of barley straw (Tab. 3). Farmer 3, for example, proposed removing barley straw, combined with a high seeding rate ( 8 to $10 \mathrm{~kg} \mathrm{ha}^{-1}$ ) and mechanical weeding, while Farmer 5 proposed to combine a high seeding rate with nitrogen input ( $80 \mathrm{~kg}$ of $18-46$ fertilizer) and the application of a broadleaf herbicide, if necessary.

\subsubsection{Origin of the diversity of modalities designed for camelina inclusion and management}

Based on the cross-cutting analysis, we identified different factors explaining the diversity of the proposals explored during the workshop to include and manage camelina. First of all, the type of soil involved seems to have had an impact on the technical itineraries designed. For example, the introduction of camelina in soils with low potential such as shallow limestone or sandy soils, typical of the region $\left(\mathrm{n}^{\mathrm{0}} 5,6,8,9,10\right)$, led some of the farmers to propose nitrogen and possibly phosphorus inputs (Tab. 3). More precisely, for these three proposals, the farmers specifically justified the choice to fertilize based on the characteristics of their soil: "it's quite shallow soils [...], so I plan to add nitrogen" (Farmer 6) or "[...] I put nitrogen on here [...] and I think phosphorus as well, when I sow to get the crop emerged, especially in these types of soils, the limestone ones, where nothing is released at all" (Farmer 5). On the contrary, for the other proposals in soils with higher mineral element supplies, such as deep loamy soils, no fertilizers were applied. A second factor explaining the diversity of modalities designed is the type of tillage that the farmer uses. For example, in the context of a no-till cropping system $\left(n^{\circ} 10\right)$, the farmer concerned proposed a relatively complex cropping system with intercrops (including camelina), particularly for short- and long-term weed management. This farmer was the only one to propose intercrops, in line with his imperative need 
to have high soil cover, to control weeds (Tab. 2). Similarly, the abovementioned difference in camelina sowing rates when introduced after canned pea (proposal $\mathrm{n}^{\mathrm{o}} 1$ and 2 ) is due to the use of direct sowing, which led Farmer 2 to anticipate potential plant loss associated with his no-till planting method. A third factor of diversity in the modalities designed is the possession of specific equipment. For example, while most of the proposals (3 out of 4) proposed to introduce camelina as a double crop when included after winter barley, Farmer 6 proposed a relay sowing, which he justified based on his access to a seeder suitable for broadcast sowing. Finally, a fourth factor is the commitment of some of the farmers to agrienvironmental measures that led to exploring low-inputs camelina crop management routes (Tab. 3). For example, in his management proposal, Farmer 9 suggested combining late sowing ("when the soil is warm") with a high seeding density $\left(10 \mathrm{~kg} \mathrm{ha}^{-1}\right)$ and possibly with a stale seed bed ("conditions permitting") to avoid herbicide treatment instead of choosing chemical weeding.

\subsection{The expected functions of introducing camelina in cropping systems}

The cross-cutting analysis of the modalities designed during the workshop showed that each farmer was reasoning the introduction of camelina according to its own objectives, expectations and constraints. For example, since camelina is a short-cycle spring crop that can be grown with a low level of inputs and from which economic value can be extracted, some of the farmers presented it as a crop that could be used to valorise, both agronomically and economically, "low-potential" soils (which can correspond to different types of soil depending on the farm). According to these farmers, introducing camelina contributes to lengthening and diversifying the crop sequences practiced on these types of soil, which are often short and mainly composed by winter crops. In the long term, it would therefore improve weed control at the crop sequence level (Tab. 2), which would indirectly lead to input savings. Furthermore, when introduced as a second crop, it could contribute to increasing margins, in soils where yield targets for the main crops may be limited.

Based on these same characteristics (short cycle, low inputs, economic valorization), some of the farmers also presented camelina as a suitable crop to meet regulatory requirements. Thus, in the case of the introduction after a canned pea crop $\left(\mathrm{n}^{\mathrm{o}} 1\right.$ and 2), camelina was presented as " $a$ solution to meet a regulatory aspect" (Tab. 2). In these situations, camelina replaces the mandatory catch crop after a canned pea crop to limit nitrates leaching into groundwater. Conversely, in cropping systems that include intermediate energy catch crops as part of a methanation project, camelina, introduced as a spring crop, meets the regulatory requirement to grow a crop with economic value between two energy catch crops $\left(n^{\circ} 7\right)$.

Finally, as a crop suited to low-input management and potentially allowing for input reduction on the following crops (e.g., by removing an aphid treatment and chemical weeding for a late-sown wheat after introducing camelina as a second crop, $\mathrm{n}^{\circ} 5$ ), camelina appears to provide an opportunity to meet the objectives of the agri-environmental measures to which some farmers are committed (Tab. 2).

\section{Discussion}

\subsection{How does the proposed organization of the workshop influence farmers' exploration and design process?}

\subsubsection{Originality of the workshop}

The design workshop developed in this study is characterized by: (i) the involvement of both new and experienced farmers; (ii) the sharing of local knowledge only, produced within a participatory and multi-stakeholder approach; and (iii) a situated design (each farmer designs for its own situation). This organization differs from those usually implemented for design workshops (Jeuffroy et al., forthcoming). First, for farmer-oriented design workshops, the same group of farmers is usually gathered in time to work successively on each other situation and it is quite rare that the group integrates new farmers (Guillier and Cros, 2020; Puech et al., 2021). Second, knowledge sharing is very rarely based on local knowledge only. Usually, the sharing of generic knowledge by scientific experts on processes and on the effects of different practices on these processes (Reau et al., 2018), or the sharing of knowledge derived from innovation tracking or diagnoses of practices (Ravier et al., 2018) is favoured. Finally, during the development of cropping system prototypes, whether in the case of peer farmers envisaging a cropping system for a central farmer (Reau et al., 2012) or in the case of design workshops not catering to a specific farmer (LesurDumoulin et al., 2018; Pelzer et al., 2020), participants never design for their own situation or for the near future. This in the interests of stimulating exploration: "everyone carries out the exercise with a certain detachment and great open-mindedness, since it does not apply to them directly or immediately" (Reau et al., 2018).

\subsubsection{Mixing new and experienced farmers: an enhancer for exploration and knowledge production?}

Knowledge exchanges between farmers with different knowledge background has been shown to be a key element in the design and the adoption of agroecological innovations by farmers (Kroma, 2006; Dolinska and d'Aquino, 2016; Garbach and Morgan, 2017; Girard and Magda, 2018). Therefore, it has been the base of several approaches to support co-design of innovative management and cropping systems (Lefèvre et al., 2014; Husson et al., 2016; Falconnier et al., 2017; Richard et al., 2020). For instance, Richard et al. (2020) proposed to bring together in workshops two types of farmers: recipients (defined as "farmers whose methods in line with current regulations are insufficient to guarantee the quality of groundwater") and advisers (defined as "farmers who have expertise and knowledge to help the recipients to design new practices"). The sharing of the advisers' experiences during a first workshop allowed the recipients designing new management practices and discussing them during a second workshop. Similarly, in our study, we observed that, during the debriefing phase, discussions were more developed for "new" farmers, as they were able to benefit from the experience of the old ones to refine their proposals - sometimes still undecided - or answer their questions. On another hand, the involvement of new farmers with new constraints and objectives also contributed to 
the expansion of the knowledge base available to support locally the introduction of camelina in the cropping systems. Indeed, as formalized by the $\mathrm{C}-\mathrm{K}$ theory (Hatchuel and Weil, 2003, 2009), the exploration of new ideas allowed by the involvement of new farmers resulted in the production of new knowledge or the identification of new knowledge gaps. For instance, Farmer 7, who had a methanation unit, proposed a very specific way to include and manage camelina adapted this form of valorization that enriched the catalogue available for other farmers to get inspired.

\subsubsection{Mobilizing only local knowledge: what impact on design?}

Conceptual models and functional scheme are traditionally used to support design processes based on agronomic diagnoses (Loyce and Wery, 2006). By proposing situated models - models that do not cover all existing processes but represent only those for which an impact has been shown locally and under the experimental conditions -, this workshop sought to foster the sharing of directly actionable knowledge, that is, knowledge that could be used by farmers in their design on their farms (Avenier and Schmitt, 2007; Faugère et al., 2010). Several examples show that this knowledge was effectively mobilised by the farmers. A first example was the choice, by all the farmers, of a high sowing rate ( 8 to $10 \mathrm{~kg} \mathrm{ha}^{-1}$ ) in the case of camelina as a single crop. Indeed, the significant effect of a high sowing rate on weed biomass, had been demonstrated in different local conditions (Leclère et al., 2019) and shared with farmers. Farmer 7 thus argued: "as I will sow camelina as pure crop, the idea would be to try the double density, to limit weed pressure". A second example is based on the Farmer 10 proposal. This farmer proposed to reduce barley sowing rate (compared to what had been tested before in the trials) and justified it with the following statement: "based on the competition that you [referring to the facilitator] have shown".

However, this methodological choice to focus on local knowledge limited the information shared to the types of soil and scenarios explored, which might have restricted design. For example, Farmer 2 questioned the possibility of introducing camelina in clay soils, characterized by successive excesses and shortages of water (according to this farmer). As this type of soil had not been explored during the different trials, the discussion during the workshop did not result in a concrete proposal, due to a lack of knowledge ("we don't have any hindsight, we'll have to test it"). Subsequent analysis of the scientific literature did nevertheless show that camelina is indeed sensitive to hydromorphy (Gesch and Cermak, 2011; George et al., 2015). An overview of this non-local scientific knowledge during the knowledge-sharing stage could therefore have been useful to this farmer in his design process. Furthermore, the introduction of camelina generally did not lead to significant redesign of the farmers' respective cropping systems, as initially assumed. An exception was for the proposal $\mathrm{n}^{\mathrm{O}} 5$ where, subsequent to the introduction of camelina as a second crop after barley, the farmer proposed removing an aphid treatment and weeding on the following wheat crop. In the other cases, the introduction of camelina sometimes led to a change in the rotation (e.g. removing the rapeseed crop in proposal $n^{\circ} 4$ ), but generally did not impact the rest of the cropping system. However, in several cases (e.g. Farmers 4, 7 and 10), a possible allelopathic effect of camelina on the following crop (sunflower, sorghum or wheat) was discussed. While no trials were conducted on this topic locally, we can posit that sharing knowledge on the previous effects of camelina, reported in the literature (e.g. the previous effect of camelina on wheat in Montana, Obour et al. (2018)) could have caused the farmers to change the management of other crops in the rotation as well, as is generally the case in design workshops (Petit et al., 2012; Pelzer et al., 2017).

\subsubsection{Designing for one's own situation: what are the risks of a fixation effect?}

To avoid the potential fixation effects (i.e. focusing on a small number of very restricted solutions) classically encountered in collective design processes (Agogué et al., 2014a, 2014b), Reau et al. (2018) have proposed carrying out non-situated and long-term design. In this study, while the inclusion of camelina after winter barley was proposed three times (albeit with different management options), the proposals of the other six farmers were different. Moreover, the sharing of proposals including technical elements that still needed be specified or that required long-term changes attests to exploration, by some farmers, beyond what is "technically feasible and technically possible tomorrow on my farm", which can lead to fixation effects. However, for other farmers, the exploration could have been broader by moving beyond the situated-design guidelines. For example, Farmer 9 mentioned: "in the case of my rotation, I could consider intercropping camelina with pea [in the spring] but since I'm not equipped, I'm putting it [camelina] as a single crop". Finally, the choice to have the farmers detail the proposal(s) they designed, at the expense of discussions between peers (only 10 minutes for each proposal), may also have limited the collective exploration of alternative solutions that frequently emerge from such interactions. Alternative proposals put forward by peers were recognized as potentially interesting, but were not expanded on by the participants due to a lack of time.

\subsection{The design workshop: a knowledge-production tool to support the introduction of camelina at a regional scale?}

Despite some of the limitations discussed above, the design workshop supported nine farmers - experienced with or new to camelina - in their redesign process. During this workshop, each of them was able to think about a cropping system proposal that they could implement on their farm to grow camelina, whatever their initial level of knowledge.

In this section, we will discuss the extent to which the analysis of the proposals developed during the workshop produces knowledge that could be mobilised by new farmers (particularly from the biorefinery's supply area) who would also like to introduce this new crop on their farms. Indeed, several studies have showed the role of sharing widely innovations implemented and their underlying agronomic logic (also called on-farm innovation tracking) to support other farmer in their design process (Salembier et al., 2016; Blanchard et al., 2017; Verret et al., 2020; Périnelle, 2021). 
More precisely, based on the cross analysis of 12 case studies, Salembier (2019) showed that, in practice, various types of agronomic contents are generated to share and disseminate learning from innovation tracking in order to foster these innovations elsewhere. In our case, the main difference is that our analysis is not based on already tested and assessed cropping systems but on "virtual" proposals. However, the potential of the resources produced to be support for design, after formalization, can be discussed based on already existing agronomic contents.

The "decision tree" concept was developed within the framework of the Mixed Technological Network (MTN) "Innovative Cropping Systems", with a view to producing resources for action based on the analysis of innovative systems (Petit et al., 2012). More specifically, these decision trees allow representing each cropping system as a combination of techniques designed to meet an objective. Thus, by making it possible to represent both the farmer's rationale and the coherence of their choices for managing the cropping system and for tailoring it to other contexts, these decision trees, widely used in the MTN have emerged as useful and effective resources for supporting in-depth transformations of cropping systems (Reau et al., 2016). Within the framework of the Dephy network, these decision trees are also used to "demonstrate successful low-pesticide cropping systems, and to help other farms outside the network adopt these winning strategies, to facilitate 'generalization'". Similarly to these decision trees, transcribing and sharing crop sheets, including the farmers' objectives and the technical levers they use, could be a resource for agricultural advisors in the area in particular, to help new farmers introduce camelina on their farms. With this in mind, the crop sheets were shared between the farmers and the local advisor.

Based on the analysis of the outputs of on-farm innovation tracking on intercrops with legumes, Verret et al. (2019) have also highlighted that the design of new intercrops by farmers can be supported and stimulated by: (i) sharing the diversity of intercrops grown locally; and (ii) creating exploration trees, linking objectives to a set of technical options that can be used to reach them, by revealing the associated agronomic processes. Thus, the cross-cutting analysis of the proposals, which enabled us both to present a range of camelina insertion and management modalities (Sect. 3.1) and to highlight the functions expected of this crop (Sect. 3.2), could, after being formalized and shared, be used in future design processes.

Finally, in the context of the agroecological transition and the emergence of a new design regime revolving around farmer as the designers of their own system (Salembier et al., 2018), questions are now being raised about the knowledge sharing to support this design process, particularly through the development of collaborative online tools (Guichard et al., 2015; Trouche et al., 2016). Based on a diagnosis of the uses of these tools and more broadly on the resources mobilized by farmers and advisors involved in a design process, Quinio et al. (2019) have proposed three resource prototypes that could be integrated into these tools to support design: (i) tables linking knowledge on pests' biological cycles to farmers' practices likely to control them and the associated functional processes; (ii) exploration trees presenting a wide range of technical options to achieve a given objective; and (iii) decision schemes highlighting the systemic aspects of agronomic solutions. Based on this work, it appears that the functional scheme presented during the knowledge sharing stage, the transcriptions of the crop sheets, and the cross-cutting analysis of the proposals could be used to feed a collaborative web tool to help farmers design cropping systems that include camelina and are tailored to their specific situation.

\section{Conclusion}

Using the example of camelina, we illustrated the importance of tailoring classic agronomic design methods, such as design workshops, and combining them with local, participatory knowledge-production approaches to support farmers in their transition toward more diversified cropping systems. By integrating the expectations of the stakeholders in the value chain from the start of the design process, this type of participatory and multi-stakeholder approach is instrumental to fostering the development of sustainable local value chains.

\section{Supplementary Material}

\section{French version.}

The Supplementary Material is available at https://www.ocljournal.org/10.1051/ocl/2021023/olm.

Acknowledgments. This work was performed, in partnership with the SAS P.I.V.E.R.T., within the frame of the French Institute for the Energy Transition (Institut pour la Transition Énergétique - ITE) P.I.V.E.R.T. (www.institut-pivert.com) selected as an Investment for the Future ("Investissements d'Avenir"). This work was supported, as part of the Investments for the Future, by the French Government under the reference ANR-001-01. This work would never have been possible without the participation and active contribution of all the farmers who attended the workshop. We warmly thank them. We also want to thank all the people (researchers, technical staff, interns) who contributed to the production of the knowledge shared in this workshop. Finally, we are grateful to Elizabeth Libbrecht for her help in traducing this paper, initially written in French.

Conflicts of interest. The authors declare no conflict of interest.

\section{References}

Agogué M, Kazakçi A, Hatchuel A, et al. 2014a. The impact of type of examples on originality: explaining fixation and stimulation effects. J Creat Behav 48: 1-12. https://doi.org/10.1002/jocb.37.

Agogué M, Poirel N, Pineau A, Houdé O, Cassotti M. 2014b. The impact of age and training on creativity: A design-theory approach to study fixation effects. Think Ski Creat 11: 33-41. https://doi.org/10.1016/j.tsc.2013.10.002.

Avenier M-J, Schmitt C. 2007. Élaborer des savoirs actionnables et les communiquer à des managers. Rev Fr Gest 174: 25-42.

Berthet ETA, Bretagnolle V, Segrestin B. 2014. Surmonter un blocage de l'innovation par la conception collective. Cas de la réintroduction de luzerne dans une plaine céréalière. Fourrages 217: 13-21. 
Berti M, Gesch R, Eynck C, Anderson J, Cermak S. 2016. Camelina uses, genetics, genomics, production, and management. Ind Crops Prod 94: 690-710. https://doi.org/10.1016/j.indcrop.2016.09.034.

Blanchard M, Vall É, Loumbana BT, Meynard J-M. 2017. Identification, caractérisation et évaluation des pratiques atypiques de gestion des fumures organiques au Burkina Faso : sources d'innovation? Autrepart 81: 115-134.

Catalogna M, Dubois M, Navarrete M. 2018. Diversity of experimentation by farmers engaged in agroecology. Agron Sustain Dev 38: 50. https://doi.org/10.1007/s13593-018-0526-2.

Colombo L, Guccione GD, Canali S, Iocola I, Antier C, Morel K. 2020. An action-research exploration of value chain development from field to consumer based on organic hempseed oil in Sicily. OCL 27: 12. https://doi.org/10.1051/ocl/2020049.

Deytieux V, Cordeau S, Fontanieu G, Moreau D, Voisin A-S, MunierJolain N. 2018. Atelier de co-conception des systèmes de culture de la plateforme CA-SYS. In: Atelier de Conception de La Plateforme CA-SYS, Dijon, France.

Dolinska A, d'Aquino P. 2016. Farmers as agents in innovation systems. Empowering farmers for innovation through communities of practice. Agric Syst 142: 122-130. https://doi.org/10.1016/ j.agsy.2015.11.009.

Falconnier GN, Descheemaeker K, Van Mourik TA, Adam M, Sogoba B, Giller KE. 2017. Co-learning cycles to support the design of innovative farm systems in southern Mali. Eur J Agron 89: 6174. https://doi.org/10.1016/j.eja.2017.06.008.

Faugère E, Navarrete $M$, Charles $M$, et al. 2010. Des connaissances scientifiques en quête de connaissances d'acteurs. NSS 18: 395403. https://doi.org/10.1051/nss/2011002.

Garbach K, Morgan GP. 2017. Grower networks support adoption of innovations in pollination management: The roles of social learning, technical learning, and personal experience. $J$ Environ Manage 204: 39-49. https://doi.org/10.1016/j.jenv man.2017.07.077.

George N, Hollingsworth J, Kaffka S. 2015. A guide for canola and camelina research in California. Univ Calif Davis Dept Plant Sci.

Gesch RW, Cermak SC. 2011. Sowing date and tillage effects on fallseeded camelina in the northern corn belt. Agron J 103: 980-987. https://doi.org/10.2134/agronj2010.0485.

Girard N, Magda D. 2018. Les jeux entre singularité et généricité des savoirs agro-écologiques dans un réseau d'éleveurs. Rev Anthropol Connaiss 12(2): 199-228. https://doi.org/10.3917/ rac.039.0199.

Girard N, Navarrete M. 2005. Quelles synergies entre connaissances scientifiques et empiriques? L'exemple des cultures du safran et de la truffe. NSS 13: 33-44. https://doi.org/10.1051/nss/2005004.

Guichard L, Ballot R, Halska J, et al. 2015. AgroPEPS, a collaborative web tool of knowledge management to share, practice, inform on sustainable cropping systems. Innov Agron 43: 83-94.

Guillier M, Cros CRR. 2020. AUTO'N-Améliorer l'autonomie azotée des systèmes de culture en Champagne crayeuse. Innov Agron 79: 193. https://doi.org/10.15454/6frb-e556.

Hatchuel A, Weil B. 2003. A new approach of innovative design: an introduction to CK theory. In: DS 31: Proceedings of ICED 03, the 14th International Conference on Engineering Design, Stockholm.

Hatchuel A, Weil B. 2009. CK design theory: an advanced formulation. Res Eng Des 19: 181-192. https://doi.org/ 10.1007/s00163-008-0043-4.

Husson O, Tran Quoc H, Boulakia S, et al. 2016. Co-designing innovative cropping systems that match biophysical and socioeconomic diversity: The DATE approach to Conservation
Agriculture in Madagascar, Lao PDR and Cambodia. Renew Agric Food Syst 31: 452-470. https://doi.org/10.1017/ S174217051500037X.

Jeuffroy M-H, Loyce C, Lefeuvre T, et al. Design workshops for innovative cropping systems and decision-support tools: learning from 12 case studies. Submitted to EJA.

Kroma MM. 2006. Organic farmer networks: Facilitating learning and innovation for sustainable agriculture. J Sustain Agric 28: $5-$ 28. https://doi.org/10.1300/J064v28n04 03 .

Kuokkanen A, Mikkilä M, Kuisma M, Kahiluoto H, Linnanen L. 2017. The need for policy to address the food system lock-in: A case study of the Finnish context. J Clean Prod 140: 933-944. https://doi.org/10.1016/j.jclepro.2016.06.171.

Lacombe C, Couix N, Hazard L. 2018. Designing agroecological farming systems with farmers: A review. Agric Syst 165: 208220. https://doi.org/10.1016/j.agsy.2018.06.014.

Lançon J, Wery J, Rapidel B, et al. 2004. Prototyping crop management systems for specific cotton growing conditions. In: Proc. World Cotton Res. Conf.-3 Cotton Prod, New Millenn. https://agritrop.cirad.fr/520548/ (accessed 9/4/19).

Leclère M. 2019. Introducing diversifying species into the cropping systems of a territory: combining knowledge production and design within multi-stakeholders platforms. Application to the case study of camelina in the Oise department. Thesis, Université Paris-Saclay.

Leclère M, Loyce C, Jeuffroy M-H. 2018. Growing camelina as a second crop in France: A participatory design approach to produce actionable knowledge. Eur J Agron 101: 78-89. https:// doi.org/10.1016/j.eja.2018.08.006.

Leclère M, Jeuffroy M-H, Butier A, Chatain C, Loyce C. 2019. Controlling weeds in camelina with innovative herbicide-free crop management routes across various environments. Ind Crops Prod 140: 111605. https://doi.org/10.1016/j. indcrop.2019.111605.

Leclère M, Lorent A-R, Jeuffroy M-H, Butier A, Chatain C, Loyce C. 2021. Diagnosis of camelina seed yield and quality across an onfarm experimental network. Eur J Agron 122: 126190. https://doi. org/10.1016/j.eja.2020.126190.

Lefèvre V, Capitaine M, Peigné J, Roger-Estrade J. 2014. Farmers and agronomists design new biological agricultural practices for organic cropping systems in France. Agron Sustain Dev 34: 623632. https://doi.org/10.1007/s13593-013-0177-2.

Lesur-Dumoulin C, Laurent A, Reau R, et al. 2018. Co-design and ex ante assessment of cropping system prototypes including energy crops in Eastern France. Biomass Bioenergy 116: 205-215. https://doi.org/10.1016/j.biombioe.2018.06.013.

Loyce C, Wery J. 2006. Les outils des agronomes pour l'évaluation et la conception de systèmes de culture. In: L'agronomie Aujourd'hui. Quae Éditions, pp. 77-95.

Magrini M-B, Anton M, Cholez C, et al. 2016. Why are grainlegumes rarely present in cropping systems despite their environmental and nutritional benefits? Analyzing lock-in in the French agrifood system. Ecol Econ 126: 152-162. https://doi. org/10.1016/j.ecolecon.2016.03.024.

Mary B, Beaudoin N, Justes E, Machet JM. 1999. Calculation of nitrogen mineralization and leaching in fallow soil using a simple dynamic model. Eur J Soil Sci 50: 549-566. https://doi.org/ 10.1046/j.1365-2389.1999.00264.x.

Meynard J-M., Charrier F, Fares M, et al. 2018. Socio-technical lockin hinders crop diversification in France. Agron Sustain Dev 38: 54. https://doi.org/10.1007/s13593-018-0535-1.

Morel K, Revoyron E, Cristobal MS, Baret PV. 2020. Innovating within or outside dominant food systems? Different challenges for 
contrasting crop diversification strategies in Europe. PLOS ONE 15: e0229910. https://doi.org/10.1371/journal.pone.0229910.

Navarrete M, Jeannequin B, Sebillotte M. 1997. Vigour of greenhouse tomato plants (Lycopersicon esculentum Mill.): Analysis of the criteria used by growers and search for objective criteria. J Hortic Sci 72: 821-829. https://doi.org/10.1080/14620316.1997.11515576.

Obour AK, Chen C, Sintim HY, et al. 2018. Camelina sativa as a fallow replacement crop in wheat-based crop production systems in the US Great Plains. Ind Crops Prod 111: 22-29. https://doi. org/10.1016/j.indcrop.2017.10.001.

Pelzer E, Bourlet C, Carlsson G, Lopez-Bellido RJ, Jensen ES, Jeuffroy M-H. 2017. Design, assessment and feasibility of legume-based cropping systems in three European regions. Crop Pasture Sci 68: 902-914. https://doi.org/10.1071/CP17064.

Pelzer E, Bonifazi M, Soulié M, et al. 2020. Participatory design of agronomic scenarios for the reintroduction of legumes into a French territory. Agric Syst 184: 102893. https://doi.org/10.1016/ j.agsy.2020.102893.

Périnelle A. 2021. Co-conception de systèmes de culture innovants avec 2 communautés villageoises du Burkina Faso : articulation entre traque aux innovations, prototypage participatif et expérimentations paysannes. Thèse en préparation, Université Paris-Saclay.

Petit M-S, Reau R. 2013. Le RMT Systèmes de culture innovants : un dispositif au service de l'innovation systémique, faisant évoluer le conseil et la formation en agronomie. Agron Environ Soc 3: 137-144.

Petit MS, Reau R, Dumas M, Moraine M, Omon B, Josse S. 2012. Mise au point de systèmes de culture innovants par un réseau d'agriculteurs et production de ressources pour le conseil. Innov Agron.

Plénet D, Simon S. 2015. Une démarche de conception et d'évaluation de systèmes de culture pour des vergers plus durables. Sci Eaux Territ 16: 58-63.

Puech C, Brulaire A, Paraiso J, Faloya V. 2021. Collective design of innovative agroecological cropping systems for the industrial vegetable sector. Agric Syst 191: 103153. https://doi.org/10.1016/ j.agsy.2021.103153.

Quinio M, Détienne F, Guichard L, Jeuffroy M-H. 2019. Knowledge structures to support design of cropping systems by farmers. In: Presented at the 6th International Symposium for Farming Systems Design, Montevideo, Uruguay.

Ravier C, Jeuffroy M-H, Gate P, Cohan J-P, Meynard J-M. 2018. Combining user involvement with innovative design to develop a radical new method for managing $\mathrm{N}$ fertilization. Nutr Cycl Agroecosyst 110: 117-134. https://doi.org/10.1007/s10705-0179891-5.

Reau R, Monnot L-A, Schaub A, et al. 2012. Les ateliers de conception de systèmes de culture pour construire, évaluer et identifier des prototypes prometteurs. Innov Agron 20: 5-33.
Reau R, Cros C, Leprun B, Merot E, Omon B, Paravano L. 2016. La construction des schémas décisionnels et leurs mobilistions dans le chamgent des systèmes de culture. Agric Environ Soc 6: 83-92.

Reau R, Cerf M, Cros C, et al. 2018. Ateliers de conception de systèmes de culture. Guide pour leur réalisation avec des agriculteurs.

Richard A, Casagrande M, Jeuffroy M-H, David C. 2020. A farmeroriented method for co-designing groundwater-friendly farm management. Agron Sustain Dev 40: 26. https://doi.org/10.1007/ s13593-020-00622-7.

Salembier C. 2019. Stimuler la conception distribuée de systèmes agroécologiques par l'étude de pratiques innovantes d'agriculteurs.

Salembier C, Elverdin JH, Meynard J-M. 2016. Tracking on-farm innovations to unearth alternatives to the dominant soybean-based system in the Argentinean Pampa. Agron Sustain Dev 36. https:// doi.org/10.1007/s13593-015-0343-9.

Salembier C, Segrestin B, Berthet E, Weil B, Meynard J-M. 2018. Genealogy of design reasoning in agronomy: Lessons for supporting the design of agricultural systems. Agric Syst 164: 277-290. https://doi.org/10.1016/j.agsy.2018.05.005.

Sebillotte M. 1990. Système de culture, un concept opératoire pour les agronomes. In Combe L, Picard D, eds. Les systèmes de culture. Paris : INRA, pp. 165-196.

Tchamitchian M, Martin-Clouaire R, Lagier J, Jeannequin B, Mercier S. 2006. SERRISTE: A daily set point determination software for glasshouse tomato production. Comput Electron Agric 50: 25-47. https://doi.org/10.1016/j.compag.2005.07.004.

Toffolini Q, Jeuffroy M-H, Mischler P, Pernel J, Prost L. 2017. Farmers' use of fundamental knowledge to re-design their cropping systems: Situated contextualisation processes. $N J A S-$ Wagening J Life Sci 80: 37-47. https://doi.org/10.1016/j. njas.2016.11.004.

Trouche L, Aubin S, Soulignac V, Guichard L. 2016. Construction of a semantic model for organizing knowledge dedicated to agroecology. The case of Agro-PEPS/GECO. Agron Environ Soc 6: 141-150.

Valantin-Morison M, Meynard J-M. 2012. A conceptual model to design prototypes of crop management: A way to improve organic winter oilseed rape performance in farmers' fields, in: crop management - Cases and tools for higher yield and sustainability. Fabio R. Marin, 77 p.

Verret V, Pelzer E, Bedoussac L, Jeuffroy M-H. 2019. Traque aux innovations d'agriculteurs pour la conception d'associations d'espèces incluant des légumineuses. Innov Agron 74: 143-154.

Verret V, Pelzer E, Bedoussac L, Jeuffroy M-H. 2020. Tracking onfarm innovative practices to support crop mixture design: The case of annual mixtures including a legume crop. Eur J Agron 115: 126018. https://doi.org/10.1016/j.eja.2020.126018.

Zimmer S, Liebe U, Didier J-P, Heß J. 2016. Luxembourgish farmers' lack of information about grain legume cultivation. Agron Sustain Dev 36: 2. https://doi.org/10.1007/s13593-015-0339-5.

Cite this article as: Leclère M, Jeuffroy M-H, Loyce C. 2021. Design workshop with farmers as a promising tool to support the introduction of diversifying crops within a territory: the case of camelina in northern France to supply a local biorefinery. $O C L 28: 40$. 